\title{
A multi-layered DIKW framework in education quality assurance for ensuring economic sustainability
}

\author{
Artem Artyukhov ${ }^{1, *}$, Iurii Volk $^{2}$, and Tetyana Vasylieva $^{3}$ \\ ${ }^{1}$ Department of Marketing, Academic and Scientific Institute for Business, Economics and \\ Management, Sumy State University, Rimski-Korsakov St. 2, 40007 Sumy, Ukraine \\ ${ }^{2}$ Department of Applied Mathematics and Complex Systems Modelling, Faculty of Electronics and \\ Information Technologies, Sumy State University, Rimski-Korsakov 2, 40007 Sumy, Ukraine \\ ${ }^{3}$ Head of Academic and Scientific Institute of Business, Economics and Management, Sumy State \\ University, 2, Rimski-Korsakov St., 40007 Sumy, Ukraine
}

\begin{abstract}
The paper presents an improved DIKW+DM model which allows organizing not only the workflow of information processing and knowledge acquisition (with their subsequent application to determining the socio-economic impact of the education quality system), but also a decisionmaking algorithm in order to optimize the functioning of the education quality system. A detailed description of the DIKW+DM model sublayers is given with an algorithm for logical transition between sublayers in order to provide a rational solution based on the results of data collection, their systematization and analysis. On the basis of the model, recommendations are proposed for ensuring the effective functioning of education quality systems at various levels. In addition to internal assurance of the quality of education, attention is also paid to external control of the effectiveness of this system's functioning. The sublayers of the DIKW+DM model are coupled with the criteria for educational programs quality assurance from the National Agency for Higher Education Quality Assurance of Ukraine.
\end{abstract}

\section{Introduction}

The current work attempts to use "data - information - knowledge - wisdom" (DIKW) hierarchy as a framework for education quality assurance process. Despite the fact that DIKW approach to information hierarchy is argued to be "unsound and methodologically undesirable" [1], we demonstrate that vertical relation between the layers of a DIKW pyramid can be effectively utilized for education quality assurance when complemented by specific sublayers. It is important to note that this paper is not an attempt to revise a DIKW model for general usage in information theory. As stated in [2], “...vertical-linear DIKW pyramid does not make sense. A direct line cannot be drawn from data to wisdom. Indeed, a direct line cannot even be drawn from data to information". This can be explained by constant growth of data amounts and variety of instruments for data collecting and unclear ratio between correct and incorrect data [2]. However, this paper proposes a multi-layered DIKW-based

* Corresponding author: a.artyukhov@,pohnp.sumdu.edu.ua 
framework for use in education quality assurance system and specify the higher education institution's (HEI) requirements for introduced sublayers not present in the original DIKW hierarchy. There can be seen the prospects of proposed framework in providing the Ukrainian and overseas HEIs with clear and comprehensive approach to an education quality assurance process. The multi-layered DIKW framework proposed can be scaled from single educational program evaluation up to university-level assessment of key performance indicators.

The practicality of the discussed problem in socio-economical context should be emphasised. HEIs play an important role in developing economically influential citizens. Hence, HEIs should be equipped with comprehensive and flexible decision-making instruments that shape training outcomes, thus forming a socio-economic landscape of any society. In the context of Sustainable Development Goals (SDGs), the work [3] gives a nice proposition of a framework for HEIs aimed to achieve SDG 4 "Quality Education". However, this framework focuses mainly on large-scale actions that HEIs have to undertake on their path to achieve SDG 4. A multi-layered DIKW framework proposed in the current paper contributes to achieving SDG 4 by encompassing specific HEIs' actions and requirements with an ability to scale the approach. As shown in the case studied by [4,5], higher education, economic growth and innovation ability are closely interrelated and express the ability to influence each other. Transferring this experience to Ukrainian HEIs should foster SDG 4 achieving and promote values of responsible and economically sustainable citizenship.

\section{Literature Review}

The literature review was carried out in two ways: a bibliometric analysis of an array of articles with highlighting keywords and topic clusters, as well as a detailed analysis of particular scientific papers. In the first case, the main directions of the prospective research were highlighted. The second approach specified the findings of specific authors' teams on the research topic.

The bibliometric analysis data are presented in Fig. 1 and Fig. 2. It should be noted that for the search query "DIKW", clusters of topics were identified, including knowledge management, data mining and, which is very important, decision making (Fig. 1). This conclusion allows expanding the DIKW model and adapting it in the form of DIKW+DM model (DIKW + decision making). The last block allows detailing the stage of knowledge "implementation", highlighting the optimization and management elements.

Fig. 2 shows that this topic is most in demand in sociology, psychology, economics, business and computer sciences. Thus, the study of the DIKW model as applied to the education quality is multidisciplinary, having both pedagogical and socio-economic orientation with elements of information technology [6]. This approach makes the basis of this work.

Much attention has been paid to the DIKW model by researchers in various fields since it was introduced by Ackoff in 1989 [7]. Revisions of a DIKW pyramid in the context of knowledge management contributed to understanding of knowledge management system designers of how knowledge management fits in the DIKW framework [8]. In [8], authors questioned the existing DIKW hierarchy and offered a modified model with the intention to introduce a more sound and descriptive approach. However, this discussion continued in [9] where the author questioned assumptions of previous authors and demonstrated some weak points of the proposed hierarchy. However, the task of DIKW modification to build a flexible and comprehensive tool for knowledge management and decision making in education quality processes, in our opinion, remains to be done. 


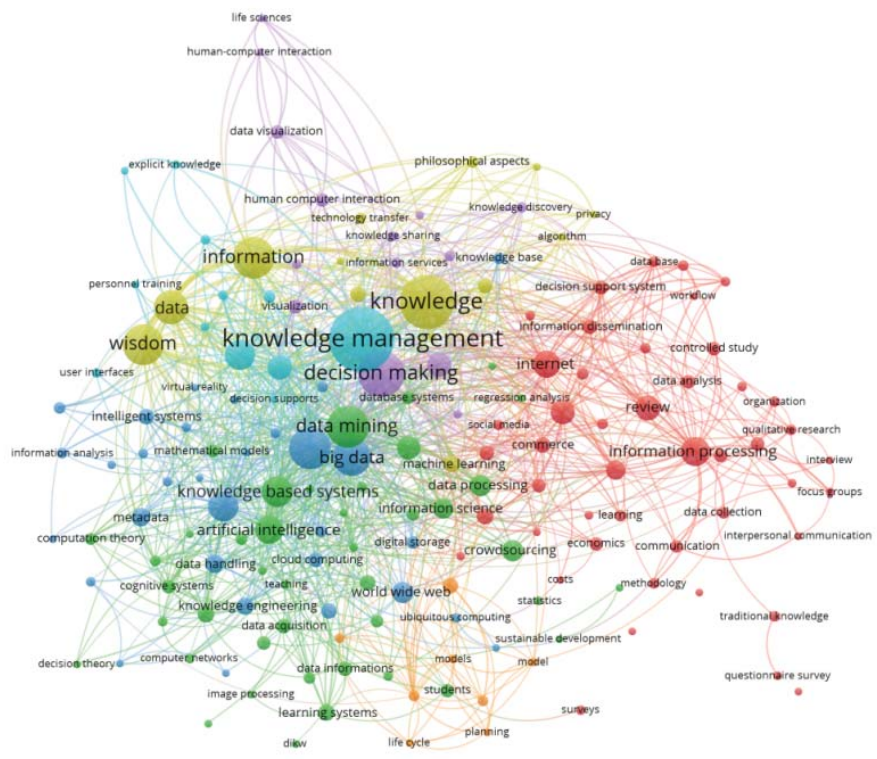

Fig. 1. A bibliometric analysis data by the query "DIKW" (data for analysis https://www.scopus.com/, 637 articles for the period of 1996-2020 analysed, a tool - VOS viewer).

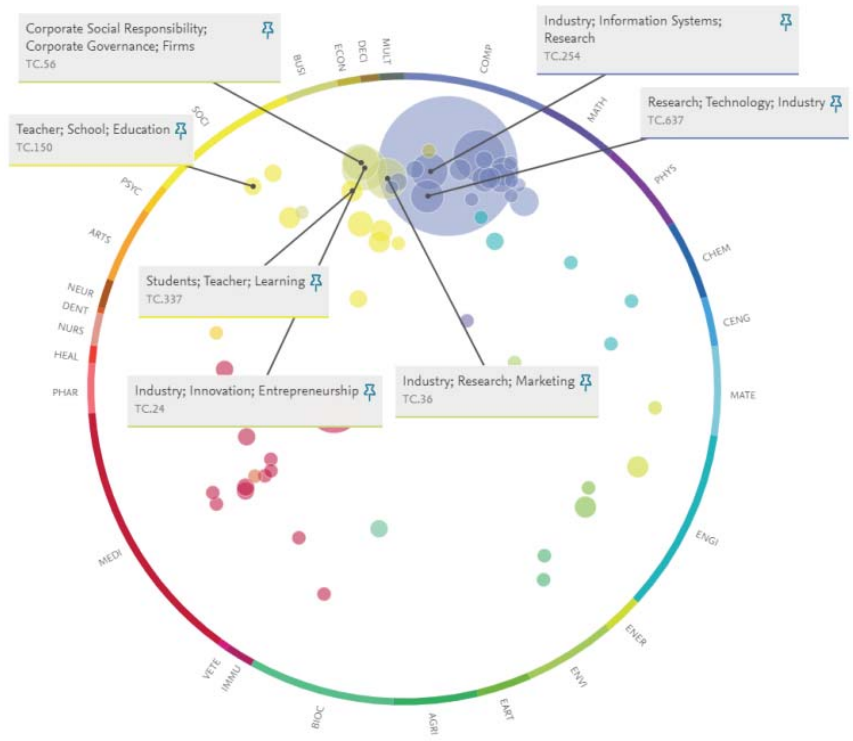

Fig. 2. A bibliometric analysis data by the query "DIKW" (data for analysis https://www.scopus.com/, tool - SciVal), top $25 \%$ of worldwide topic clusters by prominence.

The literature review also made it possible to highlight the main areas of studying the "quality of education" phenomenon and the ways to describe it, which, within the framework of this article, are the important elements of the DIKW model for the "data" and "information" blocks:

- Digitalization of education [10-13];

- Successful models for building quality systems [14-19]; 
- State regulation and management of the education quality [20-25];

- Ensuring the quality of education in subject areas [26-37];

- The quality of education and sustainable development goals [38-43].

- Development management for education [44-49].

This list is not complete, taking into account the multifactorial nature of studying the education quality system, however, it can give a general idea of the need for a comprehensive analysis of significant factors.

\section{Research Methodology, Results and Discussion}

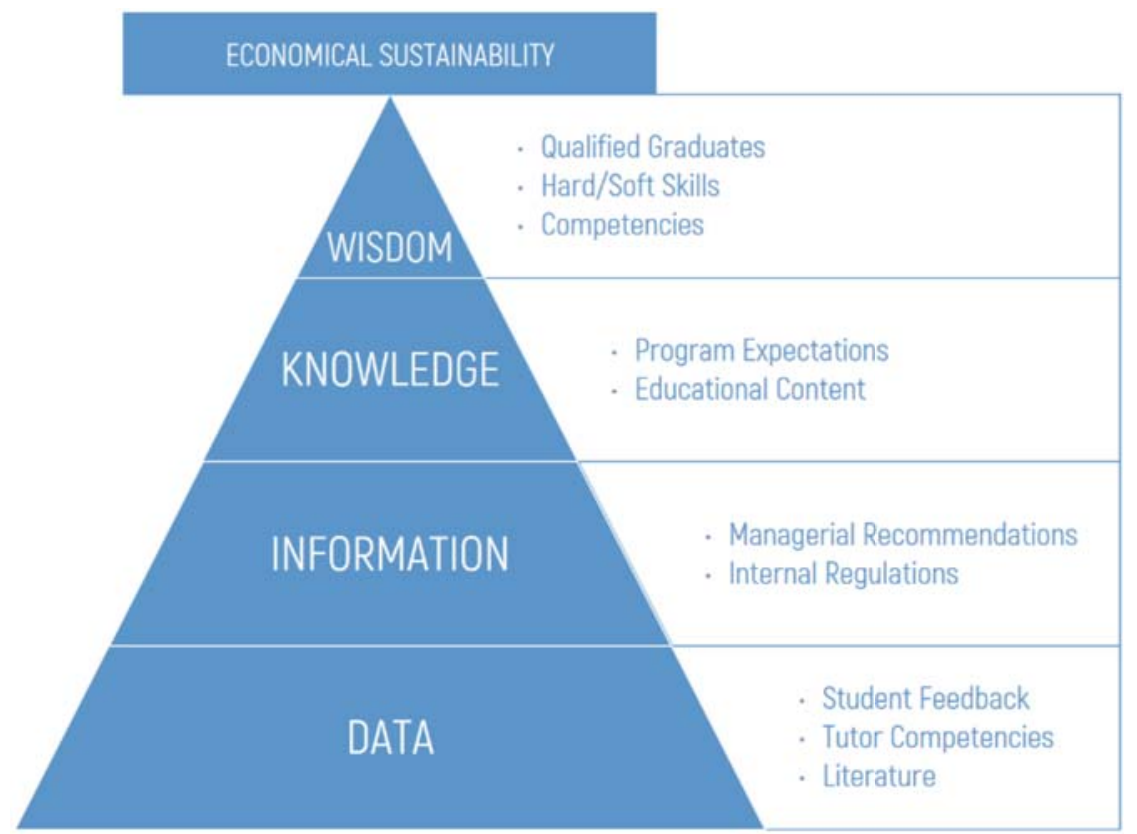

Fig. 3. A multi-layered DIKW framework for education quality assurance.

Figure 3 is an attempt to visualize a proposed multi-layered DIKW framework for education quality assurance. The framework structure consists of four main layers that are divided into sublayers, each having its goals and requirements for HEI:

- A Data layer - acting as a keystone for a DIKW framework pyramid; Data layer forms a set of grounding principles for an education quality assurance system:

- A Literature sublayer is shaped by course authors/tutors/professors utilizing available literature resources. University Requirements: library subscriptions, Internet access.

- A Tutor Competencies sublayer forms over course authors/tutors/professor competencies and qualification. University Requirements: highly trained staff.

- A Student Feedback sublayer is aimed at improving course content on the development and implementation stages. Despite that the outcome of surveys logically fits in an information layer, a Student Feedback sublayer should be considered within a Data layer, since it has the highest decision-making risk and this process should be managed on earlier stages of educational content development. University Requirements: a surveys platform (open source or proprietary), regulations to handle feedback given. 
- An Information Layer is based upon a Data layer and comprises actions taken on outcomes from a Data layer. An Information Layer is structured as follows:

- An Internal Regulations sublayer sets the handling rules for the Data layer outcomes. Utilizing a regulatory framework developed and adjusted for a particular university jumpstarts the decision making on the education quality on the earlier stages of educational processes. University Requirements: a regulatory framework that fits into the legal restrictions, staff able to follow the developed regulations.

- A Managerial Recommendations sublayer is forms according to internal regulations applied to the outcomes of the Data layer. Executives are required to conduct regular monitoring of the educational process and produce recommendations and clarifications for teaching staff aimed at enhancing educational content. University Requirements: competent managerial staff able to ensure and enforce regulations.

- A Knowledge Layer incorporates and structures outcomes of Data and Information layers. However, this layer content should not be fully encapsulated and have to remain flexible enough to accept further changes. Knowledge layer consists of the following sublayers:

- An Educational Content sublayer forms a learning infrastructure, organized in a way to utilize best educational practices applied to high-quality learning materials. University requirements: highly trained and motivated teaching staff and hardware suitable to fulfil goals set by an Information layer.

- A Program Expectations sublayer formalizes expected learning outcomes in order to provide a tool for both internal and external stakeholders to evaluate the educational process success degree. University requirements: a mechanism for stakeholder collaboration and feedback monitoring.

- A Wisdom Layer summarizes the outcomes of a Knowledge layer. The decisionmaking process aimed at economic development and sustainability should be conducted on this layer since it accumulates outcomes of previous layers. A Wisdom layer consists of:

- A Competencies sublayer should be distinguished from a Hard/Soft Skills sublayer since successful graduate may not achieve job-specific skills by the end of education but may be competent enough to adapt an individual skillset quickly for specific job or position. University requirements: an ability to train openminded graduates with a high level of fundamental knowledge in a chosen field.

- A Hard/Soft Skills sublayer represents a pool of skills that can be achieved through learning process formalized on the Knowledge layer. A set of skills achieved by graduates is formed on the basis of an educational program and individual capabilities of a graduate. University requirements: close collaboration with external stakeholders possessing hands-on experience in professions relevant to graduates.

- A Qualified Graduates sublayer forms a cohort of highly trained specialists in various fields able to perform a decision-making process aimed both at chosen specialty/position/company directly and at further professional development. University requirements: system for collaboration with alumni and employers and ability to adjust educational outcomes to their landscape of needs.

- Economic Sustainability should not be considered directly as a "Layer" in the described framework, but more as a crowning element for the effort taken by DIKW process. 2030 Agenda of Sustainable Development Goals achievement via SDG 4 [44], ensuring the growth of economic indicators [45] and assessment 
of the economic impact of the education quality on the territory development $[46,47]$ are subjects of modelling, including the model proposed in the article. At the same time, the assessment of knowledge applicability to improve the quality system is not only an important aspect, but also the development of a decision-making algorithm [48].

As an illustration of the framework viability, there are applied the Criteria for quality of educational program developed and used by National Agency for Higher Education Quality Assurance of Ukraine, (NAQA) [49] to the introduced DIKW model. This approach illustrates the scalability of the introduced multi-layered framework. For example, Criteria 1 "Design and objectives of the educational program" and 2 "The structure and content of the educational program" can be used for quality evaluation of the Data layer outcomes formulated on relevant sublayers. Criteria 3 "An access to the educational program and recognition of learning outcomes", 5 "Control measures, evaluation of higher education seekers and academic integrity", 6 "Human Resources" and 8 "Internal quality assurance of the educational program" should be used for evaluating the Information layer results. It should be noted that NAQA Criterion 6 "Human Resources", applicable to the Managerial Recommendations sublayer, is also relevant within the Educational Content sublayer of the Knowledge layer and should be used for evaluating its outcomes. Quality Criteria 4 "Teaching and learning in the educational program", 7 "Educational environment and material resources", 9 "Transparency and publicity" and 10 "Learning through research" can be applied on the Knowledge layer since its outcomes are directly related to the learning process and dissemination of its results. It should be noted that the Wisdom layer in the context of the NAQA Criteria is left unevaluated. This is explained by two factors: 1) chronological separation of the Wisdom layer due to its future-oriented specifics and 2) the counter-operationalistic nature of its sublayers' outcomes.

\section{Conclusions}

A DIKW+DM model discussed in this article deals with the criticism of the traditional DIKW model and proposes a comprehensive vertical connection between bottom and top of the pyramid in terms of education quality assurance via the set of sublayers relevant to HEIs. The proposed hierarchy encompasses processes of knowledge acquisition and management from the point of view of socio-economic impact of education quality system and considering economic sustainability as a crowning element of the DIKW+DM pyramid. Each sublayer possesses requirements for HEI in order to produce outcomes suitable for transition onto the next layer upward.

The modified DIKW framework may be of use to the Ukrainian higher educational institutions both as the basis for building internal quality assurance systems and for gaining better understanding of the assessment principles used by external evaluating bodies. The latter is illustrated by the application of criteria used by the National Agency for Higher Education Quality Assurance of Ukraine for evaluation educational programs. It should be emphasised that the proposed DIKW framework can be scaled from ensuring quality on the single educational program level up to evaluating general university performance.

Acknowledgments: This research was funded by the grant from the Ministry of Education and Science of Ukraine "Reforming the lifelong learning system in Ukraine for the prevention of the labour emigration: a coopetition model of institutional partnership" (reg. No 0120U102001), "Convergence of economic and educational transformations in the digital society: modelling the impact on regional and national security" (reg. No 0121U109553). 


\section{References}

1. M. Frické, Journal of Information Science 35, 131 (2009)

2. H. J. Van Meter, Law Tech Hum 2, 69 (2020)

3. T. Ferguson and C. G. Roofe, International Journal of Sustainability in Higher Education 21, 959 (2020)

4. H. Xu, W.-L. Hsu, T.-H. Meen, and J. H. Zhu, Sustainability 12, 2515 (2020)

5. M. S. M. Abaas, O. Chygryn, O. Kubatko, T. Pimonenko, Problems and Perspectives in Management, 16(4), 155-168. (2018).

6. T. Vasylieva, S. Lieonov, I. Makarenko, N. Sirkovska, Marketing and Management of Innovations 4, 3350-537 (2017)

7. R. L. Ackoff, Journal of Applied Systems Analysis 16, 3 (1989)

8. M. E. Jennex and S. E. Bartczak, International Journal of Knowledge Management 9, 19 (2013)

9. J. P. Carlisle, MWAIS 2015 Proceedings 8, 1 (2015)

10. C. G. Cosmulese, V. Grosu, E. Hlaciuc, and A. Zhavoronok, Marketing and Management of Innovations 3, 242 (2019)

11. P. Rubanov, S. Lyeonov, Y. Bilan, O. Lyulyov, O. Conference proceedings: The Impact of Industry 4.0 on Job Creation 21, pp. 319-328. (2019, November).

12. A. Kwilinski, O. Vyshnevskyi, H. Dzwigol, Journal of Risk and Financial Management 13(7), 142. (2020).

13. H. Yarovenko, Y. Bilan, S. Lyeonov, and G. Mentel, Journal of Business Economics and Management 22, 369 (2021)

14. H. Dźwigoł, Business Ethics and Leadership 5, 45 (2021)

15. H. Dzwigol, M. Dzwigol-Barosz, R. Miskiewicz, A. Kwilinski, Entrepreneurship and Sustainability Issues 7(4), 2630-2644. (2020).

16. M. Soliman, O. Lyulyov, H. Shvindina, R. Figueiredo, T. Pimonenko, European Journal of Tourism Research, 28. (2021)

17. N. Vardanyan, Business Ethics and Leadership 1, 93 (2017)

18. I. Skliar, Business Ethics and Leadership 2, (2018)

19. M. Mazurkiewicz, O. Liuta, and K. Kyrychenko, Business Ethics and Leadership 1, 74 (2017)

20. A. Vorontsova, T. Vasylieva, Y. Bilan, G. Ostasz, and T. Mayboroda, Administratie Si Management Public 34, 6 (2020)

21. L. Melnyk, L. Sineviciene, O. Lyulyov, T. Pimonenko, I. Dehtyarova, Problems and Perspectives in Management 16(1), 105-114. (2018).

22. O. Lyulyov, T. Pimonenko, A. Kwilinski, H. Dzwigol, M. Dzwigol-Barosz, M., V. Pavlyk, P. Barosz, Energies, 14(2) (2021).

23. S. Shkarlet, N. Kholiavko, and M. Dubyna, Marketing and Management of Innovations 3, 126 (2019)

24. M. Kordos, Marketing and Management of Innovations 3, 341-353. (2019).

25. O. Pavlenko, V. Martynets, O. Dreval, and D. Smolennikov, Calitatea: Acces La Success 21, 81 (2020)

26. K. Onopriienko, V. Onopriienko, Y. Petrushenko, and I. Onopriienko, E3S Web Conf. 234, $00002(2021)$ 
27. P. Gallo, B. Mihalcova, O. Vegsoova, T. Dzurov-Vargova, N. Busova, Marketing and Management of Innovations 2, 11-20. (2019).

28. N. Letunovska, O. Lyuolyov, T. Pimonenko, V. Aleksandrov. Paper presented at the E3S Web of Conferences, , 234 doi:10.1051/e3sconf/202123400008.

29. A. Teletov, S. Teletova, N. Letunovska. Periodicals of Engineering and Natural Sciences, 7(2), 458-465 (2019).

30. N. Letunovska, L. Saher, T. Vasylieva, S. Lieonov. Paper presented at the E3S Web of Conferences, 250 (2021).

31. L. Saher, L. Syhyda, O. Korobets, T. Berezianko. Paper presented at the E3S Web of Conferences, , 234 doi:10.1051/e3sconf/202123400011

32. I. Vakulenko, L. Saher, L. Syhyda, S. Kolosok, A. Yevdokymova. Paper presented at the E3S Web of Conferences, , 234 doi:10.1051/e3sconf/202123400020

33. A. Bondarenko, L. Zakharkina, L. Syhyda, L. Saher. International Journal of Sustainable Development and Planning, 15(4), 439-449 (2020). doi:10.18280/ijsdp.150404

34. A. Rosokhata, O. Rybina, A. Derykolenko, V. Makerska. Research in World Economy, 11 (4), 42-52 (2020).

35. A. Rosokhata, M. Minchenko, L. Khomenko, O. Chygryn. Paper presented at the E3S Web of Conferences, , 250 (2021)

36. O. Chygryn, A. Rosokhata, O. Rybina, N. \& Stoyanets. Paper presented at the E3S Web of Conferences, 234 (2021).

37. S. Lyeonov and O. Liuta, in The Financial Crisis, edited by T. Azarmi and W. Amann (Springer International Publishing, Cham, 2016), pp. 145-152

38. I. Artyukhov, T, Volk, T. Vasylieva, and S. Lyeonov, E3S Web of Conferences 250, 04006 (2021)

39. R. Miśkiewicz, R Wolniak, Sustainability, 12(14), $5776 . \quad$ (2020). https://doi.org/10.3390/su12145776

40. Y. Kharazishvili, A. Kwilinski, O. Grishnova, H. Dzwigol, Sustainability, 12(21), 8953. (2020).

41. O. Lyulyov, Y. Chortok, T. Pimonenko, O. Borovik, International Journal of Ecology and Development 30(3), 1-10. (2015).

42. O. Lyulyov, M. Paliienko, L. Prasol, T. Vasylieva, O. Kubatko, V. Kubatko, V. International Journal of Global Energy Issues, 43(2-3), 166-182. (2021).

43. J. Cebula, O. Chygryn, S. Chayen, T. Pimonenko, International Journal of Environmental Technology and Management, 21(5-6), 421-438. (2018). doi:10.1504/IJETM.2018.100592

44. E. González García, E. Colomo Magaña, and A. Cívico Ariza, Sustainability 12, 5884 (2020)

45. H. A. Faruq and A. C. Taylor, Int Adv Econ Res 17, 224 (2011)

46. E. A. Hanushek and L. Woessmann, in Handbook of International Development and Education (Edward Elgar Publishing, 2015)

47. E. A. Hanushek and L. Woessmann, The Role Of Education Quality For Economic Growth (The World Bank, 2007)

48. Y. Nurulin and I. Skvortsova, SHS Web of Conferences 44, 00064 (2018)

49. The National Agency for Higher Education Quality Assurance (NAQA), SelfAssessment Report (Kyiv, 2021) 